\title{
A Cross-Sectional Study According to Risk Factors Associated with Erectile Dysfunction in Men
}

\author{
Matthieu Marc Loposso Nkumu1, Christian Kane Kapinga1, Mafuta Tsita Alpha1, \\ Dieu Donné Moningo Molamba', Nkodila Aliosha1, Augustin Punga Maole Monga-Lembe1, \\ Jean Paul Esika Mokumo1, Diangienda Nkutima Pablo1, Mujinga Lukusa Elisabeth1, \\ Dirk De Ridder ${ }^{2}$ \\ ${ }^{1}$ Urology Division, Kinshasa University Hospital, Kinshasa, DR Congo \\ ${ }^{2}$ Urology Department, UZ Leuven, Leuven, Belgium \\ Email: mathieuloposso@gmail.com,mathieu.loposso@unikin.ac.cd,drkane14352@gmail.com, alphamafuta2019@gmail.com, \\ dmoningo@yahoo.fr, nkodilaaliocha@gmail.com,pungamaole@yahoo.com, esikajp82@gmail.com,pablodiang@gmail.com, \\ lisamlloposso@gmail.com,dirk.deridder@uzleuven.be
}

How to cite this paper: Nkumu, M.M.L., Kapinga, C.K., Alpha, M.T., Molamba, D.D.M., Aliosha, N., Monga-Lembe, A.P.M., Mokumo, J.P.E., Pablo, D.N., Elisabeth, M.L. and De Ridder, D. (2020) A Cross-Sectional Study According to Risk Factors Associated with Erectile Dysfunction in Men. Advances in Sexual Medicine, 10, 104-118. https://doi.org/10.4236/asm.2020.103007

Received: May 15, 2020

Accepted: June 30, 2020

Published: July 3, 2020

Copyright ( 2020 by author(s) and Scientific Research Publishing Inc. This work is licensed under the Creative Commons Attribution International License (CC BY 4.0).

http://creativecommons.org/licenses/by/4.0/

(c) (i) Open Access

\begin{abstract}
Background: Erectile dysfunction (ED) is a common condition in general population. It has a negative impact on the couple's quality of life. In 1995, it was estimated that it affected 152 million people worldwide, and that it would affect more than 322 million people in 2025 with a large increase in developing countries. Several studies have suggested a causal link between ED and cardiovascular disease. In the Democratic Republic of Congo, no studies exist on this subject. Nonetheless, we are seeing increased promotion on the management of sexual disorders in our media, which could testify to the extent of this problem. Objective: To assess the extent of cardiovascular risk factors for ED in Kinshasa. Material and Methods: This is a cross-sectional study for analytical purposes. It collected several categories of individuals from May 1 to October 31, 2018. The severity of ED was assessed by the IIEF-5 score and the associated risk factors sought via logistic regression. Results: The mean age of the respondents was $59.9 \pm 19.2$ years, more than half of the respondents were over the age of 60 years old (60\%). The ED proportion was $78.8 \%$, and $75 \%$ of respondents had at least moderate ED. This anomaly was significantly elevated among respondents aged over 60 years (94.8\%), diabetics (87.5\%), hypertensive patients $(92.3 \%)$ and stroke victims $(86 \%)$. The independently associated risk factors were: age $>60$ years [ORa: 9.87; 95\% CI: $6.42-10.48, p<0.001$ ], diabetes mellitus [ORa: 2.99; 95\% CI: $1.80-4.95, p=$ 0.013 ] and the stroke [ORa: 2.1; 95\% CI: $1.36-3.39 ; p=0.012 \%$ ]. The age threshold predicting ED was 67 years. Conclusion: ED is a frequent disorder
\end{abstract}


in our environment and likely to affect the quality of life of men who suffer from it. There is an ED and cardiovascular risk factors correlation. A proactive attitude of the caregiver in current practice would allow early detection of ED with a view to early and optimal management.

\section{Keywords}

Risk Factors, Erectile Dysfunction, IIEF-5, Cardiovascular Diseases, Simple Linear Correlation

\section{Introduction}

Erectile dysfunction (ED) is a common condition. It affects couple's sexual and relationship life. It is defined according to 2 nd international consultation on sexual dysfunctions as persistent or recurrent inability for man to obtain or maintain a sufficient erection of penis to allow sexual intercourse [1].

Nowadays, epidemiological studies have suggested a causal link between ED and cardiovascular disease [2]. The vascular origin hypothesis seems to be preeminent in elderly population especially if there are cardiovascular risk factors such as high blood pressure, dyslipidemia and diabetes mellitus [3]. Erectile function seems to represent a general health and cardiovascular health of man barometers. The severity of this disorder can be assessed by the international index erectile function in its simplified version (IIEF-5 Score) [4].

Global epidemiological data show an ED high prevalence. It affects $50 \%$ of men between 40 and 70 years of age and gradually increases with age [5].

A study carried out in 2002 by telephone interview with a representative sample of 1004 men aged 40 and over revealed that in France, approximately 1 in 3 men (31.6\%) would present with ED, mainly of mild intensity or moderate (according to the IIEF-5 score). In Germany, a study carried out in Cologne in men aged 30 - 80 years noted ED prevalence of 19.2\%, in Finland 74\%, in Great Britain 26\%, and in Spain 19\% [6].

In United States of America, a study guided by a scientific association devoted to men "the Massachusetts Male Aging Study (MMAS)" noted ED prevalence of $52 \%$ in men aged $40-70$ years around from Boston [7].

However, in Africa, the prevalence of ED is underestimated in most countries. Figures vary from area to area due to lack of large epidemiological surveys that can provide reliable databases. In Senegal, the overall prevalence is estimated at 26\% [8].

However, in Africa, the prevalence of ED is underestimated in most countries. In Senegal, the overall prevalence is estimated at $26 \%$ [8].

The general objective is to assess the extent of cardiovascular risk factors for Erectile dysfunction. To achieve this objective, firstly, this study set itself the goal of describing erectile dysfunction clinical characteristics.

Secondly, categorizing and identifying risk factors associated with Erectile dysfunction. 


\section{Materials and Methods}

This is a cross-sectional study for analytical purposes which took place from May to October, 2018.

\subsection{Study Population}

The present study covered several categories of people including footballers, patients hospitalized and/or followed for diabetes mellitus, stroke and High blood pressure in the 5 general hospitals selected and men senior citizens recruited in the old men home.

This study had as inclusion criteria: Be male and at least 18 years old; being hospitalized or followed for diabetes mellitus, stroke, hypertension in one of the 5 hospitals selected; Any footballer or any senior man found on the fields selected or the home of elderly the day of the investigation and have given informed consent.

The non-inclusion criteria were as follows: Have a behavioral disorder; be under the age of 18; be hospitalized for other pathologies; not having given informed consent.

The exclusion criteria were: -subjects selected but having refused the interview; -patients hospitalized for one of 3 pathologies, but who were in a coma; -Investigators did not complete the IIEF-5 score questionnaire completely.

\subsection{Operational Definitions}

Erectile dysfunction: It is a disorder of erectile function. It is assessed using the IIEF-5 Score, which is the international score for erectile function in its simplified version. This score includes a questionnaire consisting of 5 questions on whether or not to get an erection. Each question has 5 answers rated from 0 to 5 (see Appendix): Normal erectile function when the score is between 22 and 25; Mild erectile dysfunction when the score is between 17 and 21; Mild to moderate dysfunction when the score is between 12 and 16; moderate erectile dysfunction when the score is between 8 and 11; Severe erectile dysfunction when the score is between 1 and 7;

Morbid risk: this is the relationship between the waist size and the waist. When this ratio is greater than 0.5 ; so, there is a morbid risk.

Body Mass Index (BMI): It was calculated as the result of dividing the weight in kilograms squared by the height in meters.

Obesity is defined by a BMI $\geq 30 \mathrm{~kg} / \mathrm{m}^{2}$.

Insufficient weight is defined by $\mathrm{BMI}<18 \mathrm{Kg} / \mathrm{m}^{2}$.

Normal is defined by BMI between 18 and $25 \mathrm{Kg} / \mathrm{m}^{2}$.

Overweight is defined by BMI between 25.1 and $29.9 \mathrm{Kg} / \mathrm{m}^{2}$.

Mild obesity is defined by BMI between 30 and $34.9 \mathrm{Kg} / \mathrm{m}^{2}$.

Moderate obesity is defined by BMI 35 and $39.9 \mathrm{~kg} / \mathrm{m}^{2}$.

Severe obesity is defined by BMI $\geq 40 \mathrm{Kg} / \mathrm{m}^{2}$.

Abdominal obesity is defined in men by a waist size $>100 \mathrm{~cm}$. 


\subsection{Sampling}

It was for convenience with reasoned choice.

We proceeded to a draw at several degrees.

The study was conducted in five general Reference Hospitals of Kinshasa city, two of the cultural spaces (land of football) as well as one of the old men home.

Indeed in this multicentric study, the sportsmen (footballers), people in intense physical activity and the old people living in the home were included in the context of the variability of erectile function according to the physical state of people.

Thus, we had the sportsmen (intense physical activities), the elderly (reduced physical activities) as well as the patients with cardiovascular defects (high blood pressure, stroke) or linked to diabetes mellitus.

\subsection{Interest Variables}

- Sociodemographic data: Age, profession, marital status, province of origin.

- Clinical data: morphology, body mass index, medical history (High blood pressure, Stroke, Diabetes mellitus, Obesity, smoking, alcoholism, and taking stimulants (medicinal plants and aphrodisiacs...).

- Erectile dysfunction: assessed using the International Index Erectile Function using the simplified version (IIEF-5 Score).

\subsection{Collection of Data}

Before started collecting the data, we obtained approval of steering hospital committee, sports complexes authorities and elderly home director.

The eight investigators were selected from the trainee doctors after a test.

The investigators training was carried out in one session before the collected data. Conducting an interview, filling out the data collection sheets, data collection techniques and capacity building sessions on the files collection, if necessary, had constituted the purpose of the materials developed.

\subsubsection{Pre-Test or Pre-Survey Methodology}

It was carried out in Urology department of Kinshasa University hospital. Its purpose was to be able to:

Evaluate the questionnaire used;

Obtain the respondents' reactions to the questionnaire;

Estimate the duration of the study and assess the investigators.

\subsubsection{The Final Investigation}

Data collection started two weeks after the pre-survey. It took place from May to October, 2018. Before the field interview, each interviewer obtained informed consent form signed by each interviewee.

The data was collected using three collection techniques:

- The Face-to-Face Interview:

The questionnaire consisted of three types: open, closed and semi-closed. It 
was systematically offered to each person intended investigation.

Questionnaire used focused on socio-demographic, clinical characteristics and the erectile function evaluation by the use of IIEF-5 score. Interviews were conducted in French and/or in Lingala by pre-trained investigators.

- Anthropometric observation:

Weighing was carried out using balance and size was taken by using metric tape. These two parameters helped us to calculate body mass index (BMI).

- Documentary review:

Analysis of medical records for patients seen in 5 medical hospital. It was made in order to search medical histories unknown or forgotten by patients.

Tools used:

Data collection sheets, hospital and follow-up patient records for high blood pressure, diabetes mellitus, and stroke; IIEF-5 questionnaires, balance, ribbon meter, HP INTEL CORE 3 laptop, calculator and pens.

\subsection{Statisticals Analyzes}

- Data processing and analysis

After collecting data, an initial quality control was carried out in field to ensure their completeness, accuracy and reliability. A second consistency check was done to correct certain inconsistencies noted in order to guarantee validity of the results. All of these operations also helped to remove inconsistent and missing data that should not be recovered. Questionnaires were numbered using codes.

- Data processing was carried out in several stages:

Manual examination of questionnaires;

Input, purification and encoding in Excel 2010;

Analysis was performed using SPSS version 22.0 software;

Results are presented in form of tables and figures;

Descriptive analyzes performed were mean and standard deviation for quantitative data with Gaussian distribution, median for data with non-Gaussian distribution.

Pearson's Chi-square test or Fisher's exact test as appropriate was done to compare proportions. Student's T test was performed to compare means for normally distributed data.

Linear regression test was used to check IIEF-5 score and quantitative variables (age, BMI, waist size) correlation. Linear regression coefficients in single and multiple analysis were calculated to evaluate IIEF-5 score and others interests variables association.

Logistic regression was used to find ED determinants in single and multivariate analyzes with odds ratio (OR) calculation of and their confidence interval.

The ED predictive age was evaluated by ROC curve, in order to determine its threshold value, sensitivity and specificity.

Youden's index was also calculated to determine strength of this highlight (it 
must be greater than 0.5 )

For all the tests used, value of $p<0.05$ was considered as the significance threshold.

\subsection{Ethical Consideration}

Free and informed consent form was presented to each respondent who signed it before IIEF-5 questionnaire administration.

Data was collected anonymously with confidentiality guarantee.

This study presents no risk to the respondents.

\section{Results}

\subsection{Minimum Sample Size}

The sample size is estimated from the following formula:

$$
n \geq \frac{Z^{2} p(1-p)}{d^{2}},
$$

with

n: sample size

$p$ : The minimum proportion of erectile dysfunction in Africa is $24 \%$.

$d$ : the degree of precision (0.05)

$Z$ : the coefficient confidence for a $95 \%$ confidence level. For the unilateral test, $Z=1.65$.

Size is calculated for a $95 \%$ confidence interval (CI) and a degree of precision of 0.05 .

$$
n \geq 1.65^{2} \times 0.24 \times 0.76 / 0.05^{2}=199
$$

By adding 20\% of non-respondents, we obtain an equal minimum size of 199 $+0.2 \times 199=239$.

The minimum desired size was $\geq 239$ respondents distributed proportionally according to the active queue of each structure. After investigation, we obtained a sample size of 255 respondents.

\subsection{Clinical Characteristics of Respondents}

The respondents mean age was $59.9 \pm 19.2$ years old, more than half of the respondents were over 60 years old $(60 \%)$.

Overweight respondents were the most represented at $38 \%$.

In bi-varied analysis, concerning the respondents morphological characteristics, we have not noted a statistically significant risk of erectile dysfunction $(p>$ 0.05).

Stroke was the most common medical history, it was observed in 143 respondents or 56.1\%. High blood pressure and Diabetes mellitus were found in high proportions. In a bi-varied analysis, ED proportion was $87.5 \%$ in diabetics against $74.9 \%$ in non-diabetics ( $p=0.025$ ), conferring a 2 times higher risk of $\mathrm{ED}$ in diabetics than in non-diabetics. The proportion of this disorder in hyper- 
tensive patients and in patients with stroke was $92.3 \%$ and $86 \%$ respectively compared to those who did not have hypertension $(p<0.001)$ and stroke $(p=$ 0.002 ) with evaluated risk in these two groups of 5 and 3 times respectively. On the other hand, taking stimulants, gave respondents 3 times more protection compared to those who did not take stimulants $(p=0.007)$ (Table 1).

\subsection{Erectile Dysfunction Categorization and Risk Factors Associated}

\section{Score IIEF-5 and Its Determinants}

\section{1) Simple linear correlation}

IIEF-5 score was negatively and linearly correlated with age. While being statistically significant $(p<0.001)$, this correlation was strong $(r=0.856)$ (Figure 1).

BMI was significantly and negatively associated with the IIEF-5 score. The correlation was moderately strong $(r=0.661)$ (Figure 2).

\section{2) Multiple linear correlation:}

The respondents age and the BMI had emerged as major linear and negative determinants of the IIEF-5 score $\left(\mathrm{R}^{2}=0.663\right)$.

- Profile of erectile dysfunction of respondents:

The erectile dysfunction proportion increases regardless of the type of erectile dysfunction recorded with increasing age.

Table 1. Morbid history compared with erectile dysfunction.

\begin{tabular}{|c|c|c|c|c|c|}
\hline Variables & $\mathbf{N}$ & Normal Erection & Dysorder erection & OR (IC95\%) & $P$ \\
\hline \multicolumn{6}{|l|}{ Diabete mellitus } \\
\hline No & 175 & $44(25.1)$ & $131(74.9)$ & 1 & \\
\hline yes & 80 & $10(12.5)$ & $70(87.5)$ & $2.35(1.12-4.96)$ & 0.025 \\
\hline \multicolumn{6}{|c|}{ High blood pressure } \\
\hline No & 164 & $47(28.7)$ & $117(71.3)$ & 1 & \\
\hline yes & 91 & $7(7.7)$ & $84(92.3)$ & $4.82(2.06-11.19)$ & $<0.001$ \\
\hline \multicolumn{6}{|l|}{ Stroke } \\
\hline No & 112 & $34(30.4)$ & $78(69.6)$ & 1 & \\
\hline yes & 143 & $20(14.0)$ & $123(86.0)$ & $2.68(1.44-4.99)$ & 0.002 \\
\hline \multicolumn{6}{|l|}{ Tabac } \\
\hline No & 198 & $44(22.2)$ & $154(77.8)$ & 1 & \\
\hline yes & 57 & $10(17.5)$ & $47(82.5)$ & $1.34(0.63-2.87)$ & 0.447 \\
\hline \multicolumn{6}{|l|}{ Alcohol } \\
\hline No & 208 & $44(21.2)$ & $164(78.8)$ & 1 & \\
\hline yes & 47 & $10(21.3)$ & $37(78.7)$ & $0.99(0.46-2.15)$ & 0.985 \\
\hline \multicolumn{6}{|l|}{ Taking stimulant } \\
\hline No & 198 & $37(18.7)$ & $161(81.3)$ & 1 & \\
\hline yes & 57 & $17(29.8)$ & $40(70.2)$ & $0.31(0.28-0.57)$ & 0.007 \\
\hline
\end{tabular}




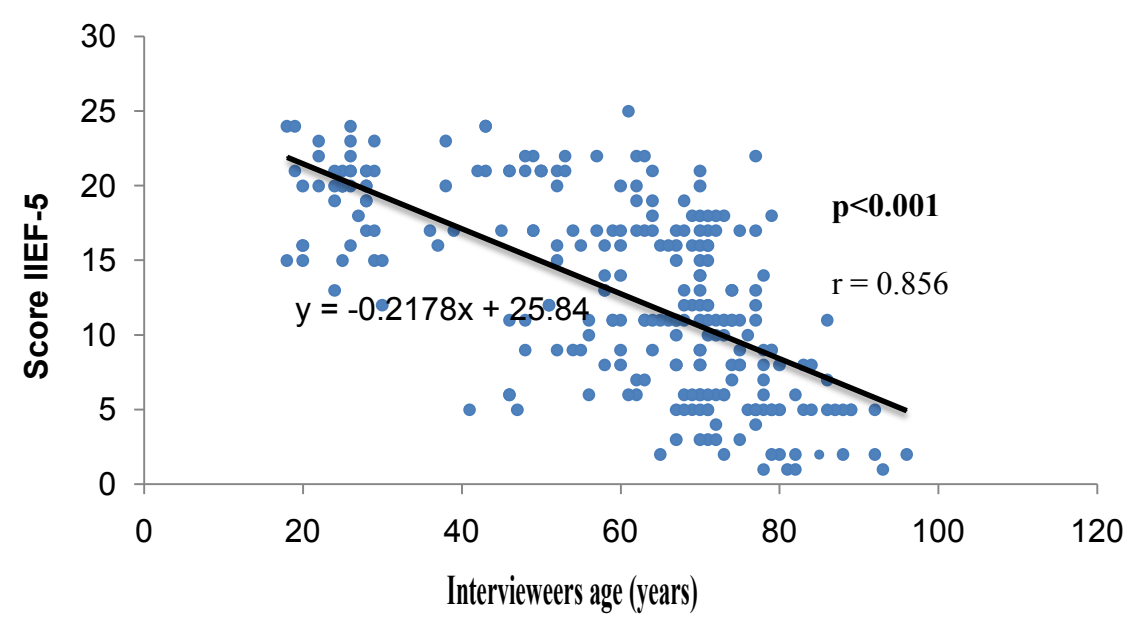

Figure 1. Simple linear correlation between IIEF5 score and age.

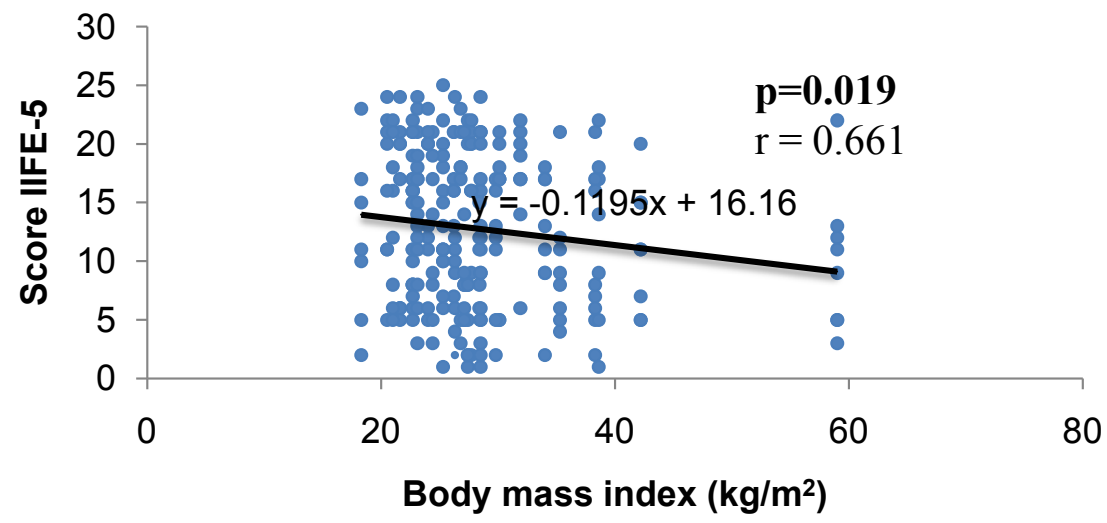

Figure 2. Simple linear correlation between the IIEF5 score and the BMI.

\section{- Factors associated with erectile dysfunction:}

In a varied, unified analysis of logistic regression, $40-60$ years and $>60$ years age group, diabetes mellitus, hypertension, stroke had emerged as determinants of erectile dysfunction in our sampling. After adjusting for all these variables, age $>60$ years (ORa: 9.87, 95\% CI: $6.42-10.48$ ), $p<0.001$ ), diabetes mellitus [ORa: 2.99, 95\% CI: 1.80 - 4.95), $p=0.013$ ) and stroke [ORa: 2.1, 95\% CI: 1.36 $3.39, p=0.012)$ were independent risk factors associated with erectile dysfunction (Table 2).

- Predictive age performance and optimal age threshold for discriminating ED: With an area under the curve of 0.871 [95\% CI (0.822 - 0.920)], age shows good predictive performance for ED. An optimal age of 67 corresponds to sensitivity of $97.7 \%$ and specificity of $94.4 \%$ (Youden's index 0.68 ).

\section{Comments}

This study was conducted to assess extent of cardiovascular risk factors for ED in Kinshasa, as it affects men and couple quality of life.

In Congolese environment, cardiovascular and metabolic pathologies (hypertension, stroke and diabetes mellitus) were found in large proportion in ED patients. 
Table 2. Factors associated with erectile dysfunction in logistic regression analysis.

\begin{tabular}{|c|c|c|c|c|}
\hline \multirow{2}{*}{ Variables } & \multicolumn{2}{|c|}{ Univariate analysis } & \multicolumn{2}{|c|}{ Multivariate analysis } \\
\hline & OR (IC 95\%) & $P$ & ORa (IC 95\%) & $\mathrm{P}$ \\
\hline \multicolumn{5}{|l|}{ Age } \\
\hline$<40$ ans & 1 & & 1 & \\
\hline $40-60$ ans & $3.03(1.35-6.81)$ & 0.007 & $2.30(0.65-8.10)$ & 0.195 \\
\hline$>60$ ans & $6.46(2.65-10.01)$ & $<0.001$ & $9.87(6.42-10.48)$ & $<0.001$ \\
\hline \multicolumn{5}{|l|}{ Diabete mellitus } \\
\hline Non & 1 & & 1 & \\
\hline Oui & $2.35(1.12-4.96)$ & 0.025 & $2.99(1.80-4.95)$ & 0.013 \\
\hline \multicolumn{5}{|l|}{ High blood pressure } \\
\hline Non & 1 & & 1 & \\
\hline Oui & $4.82(2.06-11.19)$ & $<0.001$ & $2.01(0.76-5.32)$ & 0.160 \\
\hline \multicolumn{5}{|l|}{ Stroke } \\
\hline Non & 1 & & 1 & \\
\hline Oui & $2.68(1.44-4.99)$ & 0.002 & $2.10(1.36-3.39)$ & 0.012 \\
\hline \multicolumn{5}{|l|}{ Stimulants taking } \\
\hline Non & 1 & & 1 & \\
\hline Oui & $0.31(0.28-0.57)$ & 0.007 & $0.95(0.41-2.21)$ & 0.902 \\
\hline
\end{tabular}

Similar results are reported by several authors; Bouya et al. found the following risk factors: alcoholism (75\%), smoking (25\%) and obesity (12.5\%). Erectile dysfunction was severe in $47.5 \%$ of cases and severity was correlated with age [9].

Several studies have demonstrated direct involvement of diabetes mellitus and most metabolic diseases in ED progression, this being done by altering vascular and/or nervous structures [3] [10].

Besides that, there is tobacco, which is factor not to be overlooked. Several authors have confirmed its deleterious effects on the organism and erectile function in particular. It would inhibit the activity of synthase-NO [11].

Sexual dysfunction diabetes has been associated with significantly lower quality of life and psychological distress [12]. Although sexual problems incidence increases with age.

It is mainly due to comorbid conditions associated with aging. Including smoking, heart disease, high blood pressure, high cholesterol and diabetes [13]. Incidence of erectile dysfunction in men with diabetes is three times higher than in the general population [14].

Alcohol influence in ED has been reported by several authors. Furukawa et al., noted that increased alcohol consumption was inversely correlated with erectile dysfunction assessed by the Sexual health inventory for men score [15]. Epidemiological review of ED written by Colson and Cuzin revealed frequent associa- 
tion of this entity and the excessive use of alcohol among young people [16].

Age influence on ED prevalence is well established. All ED epidemiological surveys in general population or mainly in diabetics have shown that age is strongest risk factor.

Beyond increase in ED prevalence with age, its severity is conventionally found in people of advanced age [17] [18].

In fact, all epidemiological studies on ED suggest a strong association linking erectile dysfunction and age. During age increasing, human organism undergoes a physiological aging process with, as a corollary, reduction in the trabecular musculature replaced by collagen and in mitochondria following reduction in activity and production of oxidants by mitochondrial genome degeneration, synthase-NO activity decreasing, hypothalamic-pituitary and testicular apoptosis leading to an androgenic deficit.

According to negative correlation linking BMI and IIEF-5 score, Maseroli et al. had noted no difference between obesity prevalence and overweight in two cohorts comprising general population on one hand and men consulting for erectile dysfunction on other [19].

In contrast, Van vo in Vietnam found that the main factors associated with erectile dysfunction were age, religion, history of disease, BMI, alcohol consumption, anxiety, quality of life and consensual sex with their wives/partners.

Several studies have found IIEF-5 score and BMI correlation [20] [21].

Determining exact threshold of Body Mass Index altering erections quality is useful in our field, in order to help improve the course of action for patients with $\mathrm{ED}$, which can subsequently improve their quality of life. Thus, several clinical and animal studies are required to determine this threshold.

The severe form prevalence reported could be explained by transition context marked by comorbidities in this population.

In an overall prevalence survey, Thang Van Vo found the severity of ED only $0.8 \%$ severe form and $40.8 \%$ moderate form in patients assessed by the IIEF- 5 score [21].

In a bi-varied analysis, ED proportion in diabetic and no diabetic Comparison conferring 2 times higher risk of ED in first group than second. Hypertensives and stroke victims' proportions were $92,3 \%$ and $86 \%$ respectively compared to those who did not have hypertension $(p<0.001)$ and stroke $(p=0.002)$. The developing ED risk in these two groups was assessed at 5 and 3 times respectively. On the other hand, the fact of taking stimulants, gave the respondents 3 times more protection compared to those who did not take the stimulants $(p=0.007)$.

Indeed, there is an extremely strong link between ED and cardiovascular disease. Overall, one in two patients with cardiovascular disease have ED. Epidemiological and interventional studies have shown that pathophysiological mechanisms of ED and cardiovascular disease in general are the same, it is endothelial dysfunction [22].

Diabetes mellitus, hypertension, obesity, dyslipidemia and smoking are cardiovascular risk factors and also risk factors for ED. Some authors have mentioned 
correlation between fall in IIEF-5 score and diabetes mellitus duration, poor glycemic balance and degenerative complications [23] [24].

Diabetic ED pathophysiology is multifactorial, it results from entanglement of several mechanisms namely vascular damage, dysfunction of endothelial and smooth muscle cells of erectile bodies, vegetative neuropathy and hormonal imbalances [25].

Hypertension is an ED independent risk factor. The mechanism responsible seems to be arterial disease linked to hypertension. ED severity is correlated with hypertension duration [26].

Relationship between obesity and degraded erectile function has been clearly established. Thus, pathophysiological mechanisms of obesity-related sexual dysfunction combine many factors such as local disorders due to relaxation of cavernous tissue, increase in estradiol, decrease in total testosterone and nerve signal alterations. In fact, it is mainly co-morbidities associated with obesity such as diabetes mellitus, hypertension and dyslipidemia, which are more linked to $\mathrm{ED}$, rather than the increase in BMI [21].

Age groups 40 - 60 years and above 60 years, diabetes mellitus, hypertension, stroke and stimulants taking had emerged as erectile dysfunction determinants in this population. After adjusting for all these variables, age $>60$ years (ORa: 9.87, 95\% CI: 6.42 - 10.48), $p<0.001$ ), diabetes mellitus [ORa: 2.99, 95\% CI: 1.80 - 4.95), $p=0.013$ ) and stroke (ORa: $2.1,95 \%$ CI: $1.36-3.39, p=0.012$ ) were ED independent risk factors associated. The same factors are also mentioned by several authors: Droupy S. et al. find as risk factors associated: Age, diabetes mellitus, cardiovascular disease, urogenital disorders, and all chronic diseases [27].

Oueslati I. et al. report as risk factors associated with ED: smoking, end-stage CKD and low HDLc significantly [28].

There are risk factors involved in ED occurrence of, but most remain entangled. These factors appear to be responsible for ED onset or worsening.

Predictive performance of age and optimal age threshold to discriminate respondents' erectile dysfunction:

Indeed, age and ED prevalence correlation has been demonstrated in numerous studies. Furthermore, Feldman et al., Confirm this hypothesis by reporting prevalence of $52 \%$ in men aged 40 to 70 years (7). Our study highlights the importance of "age" factor in ED occurrence at 67 years old.

Limits and strengths of the study

- Limits of presented study

Although ED is systematically analyzed for improvement of our knowledge in our environment;

There are limitations that should be mentioned: we did not resort medical imagery (penile doppler ultrasound, imagery by magnetic resonance of the erectile organs) as well as to biological assessments, in particular dosage of glycated hemoglobin, liver tests, lipidogram, assay of free and bioavailable testosterone, assay of $\mathrm{LH}$ as well as prolactin. 
Other limiting factors include:

Several categories choice can be a selection bias, however our results remain valid and give a first glimpse on ED in our environment;

Our sample is not representative of entire population of Kinshasa; therefore, our results cannot be generalized to entire population, however ED is a frequent pathology;

- Strengths of the study

It has adopted an internationally recognized questionnaire for evaluation and appreciation of male erectile function in a sub-Saharan environment, such as studies in a better equipped environment.

It is also the first study to define age at which we can predict ED in our environment;

In addition, the robustness of simple correlation between the variables continues as well as the results of multivariate analyzes constitute an obvious strength.

\section{Conclusions}

$\mathrm{DE}$ is a frequent disorder in our environment and likely to affect the quality of life of men who suffer from it;

There is cardiovascular risk factors and ED correlation;

It is therefore essential to systematically search for ED in elderly men who are carriers of cardiovascular risk factors;

Optimal age threshold predicting ED in our environment is 67 years old;

A proactive attitude of the caregiver in current practice would allow early of ED detection with a view an optimal management.

\section{Acknowledgements}

We thank the Association Congolaise d'urologie (ACU) who permits the public presentation of this research.

Secondly, we thank the international continence society (ICS) who accept this abstract for the oral presentation in the 50th ICS congress (Las Vegas, 2020).

\section{Conflicts of Interest}

The authors declare that there is no conflict of interest.

\section{References}

[1] (1993) NIH Consensus Conference. Impotence. NIH Consensus Development Panel on Impotence. JAMA, 270, 83-90. https://doi.org/10.1001/jama.1993.03510010089036

[2] Lledó-García, E., Jara-Rascón, J., Moncada Iribarren, I., Piñero-Sánchez, J., AragónChamizo, J. and Hernández-Fernández, C. (2015) Penile Prosthesis First and Replacement Surgeries: Analysis of Patient and Partner Satisfaction. The Journal of Sexual Medicine, 12, 1646-1653. https://doi.org/10.1111/jsm.12932

[3] Kizilay, F., Gali, H.E. and Serefoglu, E.C. (2017) Diabetes and Sexuality. Sexual Medicine Reviews, 5, 45-51. https://doi.org/10.1016/j.sxmr.2016.07.002 
[4] Smith, D.A. (1978) Assuring Quality Ambulatory Health Care. The Dr Martin Luther King Jr. Health Center, New York.

[5] Degauquier, C., Absil, A.S., Psalti, I. and Meuris, S.J.F. (2012) Impact of Aging on Sexuality. Revue Médicale de Bruxelles, 33, 153-163.

[6] Schouten, B.W., Bosch, J.L., Bernsen, R.M., Blanker, M.H. and Thomas, S.B.A. (2005) Incidence Rates of Erectile Dysfunction in the Dutch General Population. Effects of Definition, Clinical Relevance and Duration of Follow-Up in the Krimpen Study. International Journal of Impotence Research, 10, 58-62. https://doi.org/10.1038/sj.ijir.3901264

[7] Johannes, C.B., Araujo, A.B., Feldman, H.A., Derby, C.A. and Kleinman, K.P. (2000) Incidence of Erectile Dysfunction in Men 40 to 69 Years Old: Longitudinal Results from the Massachusetts Male Aging Study. The Journal of Urology, 163, 460-463. https://doi.org/10.1016/S0022-5347(05)67900-1

[8] Diao, B., Ndoye, A.K., Fall, P.A., Niang, L., Odzebe, A., Bah, I., Sow, Y., et al. (2007) Erectile Dysfunction in Senegal: Epidemiological Profile. Andrologie, 17, 223-229. https://doi.org/10.1007/BF03040731

[9] Bouya, A.P., Odzebe, A.W. and Mayala, R. (2012) La dysfonction érectile au Congo: Premières données sur la fréquence de ce motif de consultation et profil clinique au centre hospitalier universitaire de Brazzaville. Andrologie, 22, 92-95.

https://doi.org/10.1007/s12610-012-0169-4

[10] Naya, Y., Soh, J., Ochiai, A., Mizutani, Y., Ushijima, S., Kamoi, K., Ukimura, O., Kawauchi, A., Fujito, A., Ono, T., Iwamoto, N., Aoki, T., Imada, N., Marumo, K., Murai, M., et al. (2002) Significant Decrease of the International Index of Erectile Function in Male Renal Failure Patients Treated with Hemodialysis. International Journal of Impotence Research, 14, 172-177. https://doi.org/10.1038/sj.ijir.3900854

[11] Rossi, D. and Tostain, J. (2004) Déficit androgénique lié à l'âge: Synthèse diagnostique. Progrès en Urologie, 14, 809-830.

[12] Jacobson, A.M., Braffett, B.H., Cleary, P.A., Gubitosi-Klug, R.A. and Larkin, M.E. (2013) The Long-Term Effects of Type 1 Diabetes Treatment and Complications on Health-Related Quality of Life. Diabetes Care, 36, 3131-3138.

https://doi.org/10.2337/dc12-2109

[13] Johannes, C.B., Araujo, A.B., Feldman, H.A., Derby, C.A., Kleinman, K.P., et al. (2000) Incidence of Erectile Dysfunction in Men 40 to 69 Years Old: Longitudinal Results From the Massachusetts Male Aging Study. Journal of Urology, 163, 460-463. https://doi.org/10.1097/00005392-200002000-00015

[14] Maiorino, M.I., Bellastella, G., Della Volpe, E., Casciano, O., Scappaticcio, L. and Cirillo, P. (2017) Erectile Dysfunction in Young Men with Type 1 Diabetes. International Journal of Impotence Research, 29, 17-22. https://doi.org/10.1038/ijir.2016.38

[15] Furukawa, S., Sakai, T., Niiya, T., Miyaoka, H., Miyake, T., Yamamoto, S., et al. (2016) Alcohol Consumption and Prevalence of Erectile Dysfunction in Japanese Patients with Type 2 Diabetes Mellitus: Baseline Data from the Dogo Study. Alcohol, 55, 17-22. https://doi.org/10.1016/j.alcohol.2016.07.006

[16] Colson, M.H., Cuzin, B., Faix, A., Grellet, L. and Huyghes, E. (2018) Current Epidemiology of Erectile Dysfunction: An Update. Sexologies, 27, 9-17. https://doi.org/10.1016/j.sexol.2018.01.017

[17] Kessler, A., Sollie, S., Challacombe, B., Briggs, K. and Van Hemelrijck, M. (2019) The Global Prevalence of Erectile Dysfunction: A Review. BJU International, 124, 587-589. https://doi.org/10.1111/bju.14813

[18] Chung, E. (2019) Sexuality in Ageing Male: Review of Pathophysiology and Treat- 
ment Strategies for Various Male Sexual Dysfunctions. Medical Sciences, 7, 98. https://doi.org/10.3390/medsci7100098

[19] Palmer, M.R., Holt, S.K., Sarma, A.V., Dunn, R.L., Hotaling, J.M., Cleary, P.A., et al. (2017) Longitudinal Patterns of Occurrence and Remission of Erectile Dysfunction in Men with Type 1 Diabetes. The Journal of Sexual Medicine, 14, 1187-1194. https://doi.org/10.1016/j.jsxm.2017.07.012

[20] Andersson, D.P., Ekström, U. and Lehtihet, M. (2015) Rigiscan Evaluation of Men with Diabetes Mellitus and Erectile Dysfunction and Correlation with Diabetes Duration, Age, BMI, Lipids and HbA1c. PLoS ONE, 10, e0133121. https://doi.org/10.1371/journal.pone.0133121

[21] Van Vo, T., Hoang, H.D. and Nguyen, N.P.T. (2017) Prevalence and Associated Factors of Erectile Dysfunction among Married Men in Vietnam. Frontiers in Public Health, 5, 94. https://doi.org/10.3389/fpubh.2017.00094

[22] Fabbri, A., Caprio, M., et al. (2003) Pathology of Erection. Journal of Endocrinological Investigation, 26, 87-90.

[23] Erden, S. and Kaya, H. (2015) Sexual Dysfunction and Anxiety Levels of Type 2 Male Diabetics. Applied Nursing Research, 28, 239-243.

https://doi.org/10.1016/j.apnr.2015.04.014

[24] Oyelade, B.O., Jemilohun, A.C. and Aderibigbe, S.A. (2016) Prevalence of Erectile Dysfunction and Possible Risk Factors among Men of South-Western Nigeria: A Population Based Study. The Pan African Medical Journal, 24, 124.

[25] Gandaglia, G., Briganti, A., Montorsi, P., Mottrie, A., Salonia, A. and Montorsi, F. (2016) Diagnostic and Therapeutic Implications of Erectile Dysfunction in Patients with Cardiovascular Disease. European Urology, 70, 219-222. https://doi.org/10.1016/j.eururo.2016.01.054

[26] Soulemane, P., Soodougoua, B., Machihude, P., Kevin, T., Yaovi, A., Matchona, K. and Madikizi, M.K. (2015) La dysfonction érectile chez l'hypertendu togolais: Étude transversale chez 100 patients dans le Service de Cardiologie du CHU Campus de Lomé. The Pan African Medical Journal, 21, 47-54. https://doi.org/10.11604/pamj.2015.21.47.5401

[27] Droupy, S. (2005) Épidémiologie et physiopathologie de la dysfonction. Annales d Urologie, 39, 71-84. https://doi.org/10.1016/j.anuro.2005.04.004

[28] Khiar, I., Oueslati, M., Ounissi, S., Azaiez, E., Talbi, J. and Belagha, K. (2017) Prévalence et facteurs de risque de la dysfonction érectile chez les insuffisants rénaux chroniques. African Journal of Urology, 23, 331-337.

https://doi.org/10.1016/j.afju.2017.03.004 


\section{Appendix}

\section{The International Index Erectile Function (IIEF-5) questionnaire}

Over the past six months:

1) How do you rate your confidence that you could get and keep an erection?

-Very low-Low-Moderate-High-Very high 12345

2) When you had erections with sexual stimulation, how often were your erections hard enough for penetration?

-Almost never/never-A few times (much less than half the time)-Sometimes (about half the time)-Most times (much more than half the time)-Almost always/always 123453

3) During sexual intercourse, how often were you able to maintain your erection after you had penetrated (entered) your partner?

-Almost never/never-A few times (much less than half the time)-Sometimes (about half the time)-Most time (much more than half the time)-Almost always/ always 123454

4) During sexual intercourse, how difficult was it to maintain your erection to completion of intercourse?

-Extremely-difficult-Very difficult-Diffcult-Slightly difficult-Not difficult 123 45

5) When you attempted sexual intercourse, how often was it satisfactory for you?

-Almost never/never-A few times (much less than half the time)-Sometimes (about half the time)-Most times (much more than half the time)-Almost always/always 12345

The IIEF- 5 score is the sum of the ordinal responses to the five items; thus, the score can range from 5 to 25

The IIEF- 5 further classifies ED severity with the following breakpoints: 1 - 7 severe ED 8 - 11 moderate ED 12 - 16 mild to moderate ED 17 - 21 mild ED Figure 1. The Sexual Health Inventory for Men (SHIM) takes only two to three minutes. 